\title{
Enhanced photoelectrochemical and photocatalytic activities of CdS nanowires by surface modification with $\mathrm{MoS}_{2}$ nanosheets
}

\author{
Hongmei Wang ${ }^{1,2 \dagger^{*}}$, Sara Bonabi Naghadeh ${ }^{2 \dagger},{\text { Chunhe } \mathrm{Li}^{3}, \mathrm{Lu} \mathrm{Ying}^{1}, \mathrm{~A}^{\prime} \text { Lester Allen }}^{2}$ and \\ Jin Zhong Zhang ${ }^{2 *}$
}

\begin{abstract}
Nanocomposites composed of one-dimensional (1D) CdS nanowires (NWs) and $1 \mathrm{~T}-\mathrm{MoS}_{2}$ nanosheets have been fabricated through a two-step solvothermal process. 5 mol\% of $\mathrm{MoS}_{2}$ loading results in the best optical properties, photoelectrochemical (PEC) as well as photocatalytic activities for hydrogen evolution reaction (HER). Compared with pure CdS NWs, the optimized nanocomposite shows 5.5 times enhancement in photocurrent and 86.3 times increase for HER in the presence of glucose and lactic acid as hole scavengers. The enhanced PEC and HER activities are attributed to the intimate contact between $\mathrm{MoS}_{2}$ and CdS that efficiently enhances charge carrier separation. In addition, ultrafast transient absorption (TA) measurements have been used to probe the charge carrier dynamics and gain deeper insight into the mechanism behind the enhanced PEC and photocatalytic performance.
\end{abstract}

Keywords: $\mathrm{MoS}_{2} / \mathrm{CdS}$ nanostructures, surface modification, photoelectrochemical activity, photocatalytic hydrogen evolution, glucose and lactic acid

\section{INTRODUCTION}

To address the problems of the global energy crisis and environmental pollution, development and utilization of clean, renewable energy resources have become very urgent. Hydrogen production by solar water splitting with semiconductor photocatalysts is a promising technology based on renewable resources $[1,2]$. Since the first report on water splitting by Fujishima and Honda, $\mathrm{TiO}_{2}$ has been extensively investigated as an excellent photocatalyst due to its good stability, non-toxicity, low cost and high photocatalytic activity under UV light irradiation [3-5]. However, $\mathrm{TiO}_{2}$ can only absorb UV light that makes up approximately $5 \%$ of sunlight, resulting in low light utilization efficiency [6]. It is therefore desirable to develop efficient visible light-active photocatalysts. Many different semiconductor materials, such as metal oxide, metal sulfide and metal nitride, have been successfully demonstrated for harvesting solar energy [7-11].

As one of the potential promising candidates for visible light driven photocatalysis, cadmium sulfide (CdS) has been widely studied owing to its proper bandgap $\left(E_{\mathrm{g}}=\right.$ $2.42 \mathrm{eV}$ ) for efficient absorption of visible light [12], and its valence and conduction band positions being thermodynamically favorable for water oxidation and reduction, respectively [13]. However, the low activity and rapid photocorrosion make pure CdS photocatalyst unfavorable for hydrogen evolution reaction (HER) because photogenerated electron and hole pairs cannot be efficiently separated and transferred $[14,15]$. Loading cocatalysts on CdS to create hierarchical structures provides high activation potentials for HER and suppresses the photocorrosion of CdS [16-18]. For example, Pt as a cocatalyst could improve the photocatalytic HER efficiency of CdS [19]. However, Pt is limited due to its scarcity and high cost. Hence, searching for efficient nonprecious-etal cocatalysts as a substitute for $\mathrm{Pt}$ is an direction in the development of photocatalysis [20].

\footnotetext{
${ }^{1}$ College of Biological, Chemical Sciences and Engineering, Jiaxing University, Jiaxing 314001, China

${ }^{2}$ Department of Chemistry and Biochemistry, University of California, Santa Cruz, California 95064, USA

${ }^{3}$ Department of Physics and Key Laboratory of Artificial Micro- and Nano-structures of Ministry of Education, Wuhan University, Wuhan 430072, China

These authors contributed equally to this work.

* Corresponding authors (emails: hongmei256@163.com (Wang H); zhang@ucsc.edu (Zhang JZ))
} 
Molybdenum disulfide $\left(\mathrm{MoS}_{2}\right)$, with a layered structure composed of three stacked atom layers (S-Mo-S), has been extensively investigated as an excellent cocatalyst for facilitating separation of photoinduced carriers and reducing photocorrosion. Li et al. first reported that the activity of producing $\mathrm{H}_{2}$ for $0.2 \mathrm{wt} \% \mathrm{MoS}_{2} / \mathrm{CdS}$ was enhanced 36 times compared to pristine CdS, which was even higher than $0.2 \mathrm{wt} \% \mathrm{Pt} / \mathrm{CdS}$ under the same reaction conditions [21-22]. Following this work, $\mathrm{MoS}_{2} / \mathrm{CdS}$ nanocomposites with different physical dimensions have been constructed and applied to HER [23-28]. Among them, one-dimension (1D) CdS nanostructures have attracted considerable interests due to their large aspect ratio, high electron mobility and fast electron transport with short radial distances [27,29]. Especially, $\mathrm{MoS}_{2}$ has three phases: $1 \mathrm{~T}, 2 \mathrm{H}$ and $3 \mathrm{R}$. Among them, metallic $1 \mathrm{~T}$ $\mathrm{MoS}_{2}$ has attracted more attention in improving HER performance, due to the large exposure of edge sites, excellent electronic conductivity and high density of trap states and vacancies. Therefore, coupling 1D CdS with $1 \mathrm{~T}-\mathrm{MoS}_{2}$ would seem to be a promising approach to achieving high efficiency for solar $\mathrm{H}_{2}$ evolution.

In this work, we fabricated $\mathrm{MoS}_{2} / \mathrm{CdS}$ nanocomposite structures with the amount of $1 \mathrm{~T}-\mathrm{MoS}_{2}$ optimized for PEC and photocatalytic HER applications. Enhanced PEC activity for HER with optimal amount of $1 \mathrm{~T}-\mathrm{MoS}_{2}$ is attributed to improved charge separation and transfer in CdS facilitated by $\mathrm{MoS}_{2}$.

\section{EXPERIMANTAL SECTION}

\section{Synthesis and characterization}

All the chemicals used in all the experiments were of analytical grade and obtained from Sinopharm Chemical Reagent Co., Ltd, Shanghai. Deionized water was used in the experiments throughout. The $\mathrm{MoS}_{2} / \mathrm{CdS}$ nanocomposites were fabricated by a two-step solvothermal method, as shown in Scheme S1. The morphologies of the samples were determined with scanning electron microscopy (SEM, Hitachi S-4800), transmission electron microscopy (TEM, JEOL TEM-2010) and high-resolution transmission electron microscopy (HRTEM, JEM-2010 FEM). Elemental analysis of the samples was conducted by an energy dispersive X-ray spectrometer (EDS) attached to TEM. The crystal phases of the samples were characterized with a Bruker D8-advance X-ray diffraction (XRD), performed with $\mathrm{Cu} \mathrm{Ka}$ radiation. The results were recorded at a scan speed of $4^{\circ} \mathrm{min}^{-1}$ over the angular range $(2 \theta)$ from $10^{\circ}$ to $80^{\circ}$, and the accelerating voltage and operating current were $40 \mathrm{kV}$ and $40 \mathrm{~mA}$, respec- tively. Raman spectra were measured using an inVia Renishaw Raman system with a $514 \mathrm{~nm}$ Ar laser. The surface areas $\left(S_{\mathrm{BET}}\right)$ of the samples were measured utilizing nitrogen adsorption-desorption apparatus. Each sample was degassed at $77 \mathrm{~K}$ on an instrument (JWBK122W, China). The pore-size distribution in the Barrett-Joyner-Halenda (BJH) method was depicted using the adsorption isotherms. X-ray photoelectron spectroscopy (XPS, Thermo 163 Fisher ESCALAB 250Xi) was conducted to analyze the chemical compositions and binding energies of the samples. UV-vis diffuse reflectance spectra (UV-vis DRS) of the samples were measured using a Shimadzu UV-2550 spectrometer with $\mathrm{BaSO}_{4}$ as the internal reflectance standard. The photoluminescence (PL) spectra for solid samples were investigated on Hitachi F-7000 spectrophotometer with an excitation wavelength of $380 \mathrm{~nm}$.

\section{Photoelectrochemical measurements}

The photoelectrochemical (PEC) experiments were carried out using a three-electrode cell, where fluorine-tin oxide (FTO) electrode coated with the samples was used as working electrode, $\mathrm{Pt}$ as counter electrode, and $\mathrm{Ag} /$ $\mathrm{AgCl}$ as reference electrode. For the fabrication of working electrode, $10 \mathrm{mg}$ sample was ultrasonically dispersed into $1.0 \mathrm{~mL}$ isopropanol and $50 \mu \mathrm{L}$ nafion solution to make a slurry. The slurry was spin-coated onto a FTO glass substrate $(1 \mathrm{~cm} \times 2 \mathrm{~cm})$ and then dried at room temperature under dark condition. An aqueous solution containing $0.5 \mathrm{~mol} \mathrm{~L}^{-1} \mathrm{Na}_{2} \mathrm{SO}_{4}$ was used as the electrolyte and bubbled with $\mathrm{N}_{2}$ for 30 min prior to measurement. A $300 \mathrm{~W}$ Xe lamp equipped with an ultraviolet cutoff filter $(\lambda \geq 400 \mathrm{~nm})$ was employed as the visible light source. The PEC performance was measured using an electrochemical workstation (CHI-660D).

\section{Ultrafast transient absorption spectroscopy}

The femtosecond transient absorption (TA) measurements were carried out using a Quantronix laser system as described previously [30]. The system consists of an Er-doped fiber oscillator, regenerative amplifier and diode-pumped Nd: YLF pump laser $(527 \mathrm{~nm})$. The seed beam after amplification splits to a white light continuum probe pulse $(450-750 \mathrm{~nm})$ and feed an optical parametric amplifier with 1:9 ratio, respectively. The output of optical parametric amplifier was tuned to $390 \mathrm{~nm}$ and used to excite the samples, which were prepared as thin films using spin coating technique, with various pulse energies (750, 323 and $190 \mathrm{~nJ}$ per pulse) to study power dependence. After overlapping pump and probe on the sample 
spatially and temporally, the TA data was collected using a charge-coupled device (CCD) detector over a temporal delay interval of $0-1000$ ps between the pump and probe pulses.

\section{Evaluation of photocatalytic hydrogen production}

Photocatalytic HER was conducted in a gastight projection of glass reactor with high transparent quartz glass cover at top for illumination. Before the typical run, $0.10 \mathrm{~g}$ sample was added into $100 \mathrm{~mL}$ aqueous solution containing $2.0 \mathrm{~mL}$ lactic acid alone or $0.010 \mathrm{~mol}$ glucose and $2.0 \mathrm{~mL}$ lactic acid as sacrificial agent. The sample was treated with ultrasonication for $10 \mathrm{~min}$ and then the whole equipment was evacuated with vacuum pump for $0.5 \mathrm{~h}$ to exhaust the air in order to establish adsorptiondesorption equilibrium in the reactor. The reactant solution was stirred gently, and meanwhile the reaction temperature was maintained at room temperature by cooling circulation water. A $300 \mathrm{~W}$ Xe lamp with a $400 \mathrm{~nm}$ cutoff filter was irradiated from the top of glass reactor. The gaseous $\mathrm{H}_{2}$ inside the reactor was periodically withdrawn from the hydrogen production system and analyzed by gas chromatograph (CEL-GC7900), equipped with a thermal conductivity detector (TCD), ultra-pure $\mathrm{N}_{2}$ as carrier gas, and $5 \AA$ molecular sieve columns. The gases generated in the reaction were quantified with standard curve of $\mathrm{H}_{2}$ gas.

\section{RESULTS AND DISCUSSION}

\section{Structure, composition, and optical properties of the} samples

The morphologies of $\mathrm{MoS}_{2}$, CdS and $\mathrm{MoS}_{2} / \mathrm{CdS}$ samples were characterized by SEM. Fig. 1 show SEM images of pure $\mathrm{MoS}_{2}$ with the irregular morphology (Fig. 1a), pristine CdS with uniform and smooth 1D nanowire structures with a length of several micrometers (Fig. 1b) and $\mathrm{MoS}_{2} / \mathrm{CdS}$ nanocomposites with different amounts of $\mathrm{MoS}_{2}$ (Fig. 1c-f). The surface of CdS nanowires (NWs) becomes rougher with the increasing of $\mathrm{MoS}_{2}$ loading and still maintains the 1D nanostructures, consistent with the expectation that the surface of CdS NWs is covered by $\mathrm{MoS}_{2}$.

TEM was employed to further determine the morphologies and microstructures of $\mathrm{MoS}_{2}, \mathrm{CdS}$ and $\mathrm{MoS}_{2} / \mathrm{CdS}$ samples. The EDS (Fig. 2a, d, g, j) confirms the composition of $\mathrm{MoS}_{2}$. Due to lacey support films are used to support the samples, the elements $\mathrm{Cu}$ can be observed from EDS. Fig. 2b, c show that $\mathrm{MoS}_{2}$ nanosheets were stacked together without the CdS nanowires as growth

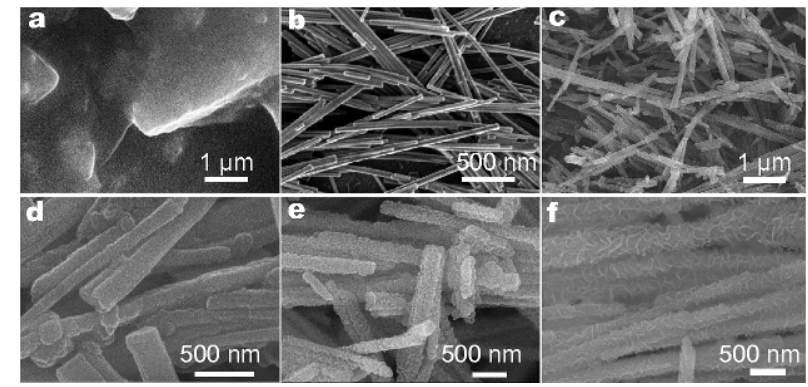

Figure 1 SEM images of (a) $\mathrm{MoS}_{2}$; (b) CdS; (c) $5 \%-\mathrm{MoS}_{2} / \mathrm{CdS}$; (d) 10\%$\mathrm{MoS}_{2} / \mathrm{CdS}$; (e) $15 \%-\mathrm{MoS}_{2} / \mathrm{CdS}$; (f) $20 \%-\mathrm{MoS}_{2} / \mathrm{CdS}$.
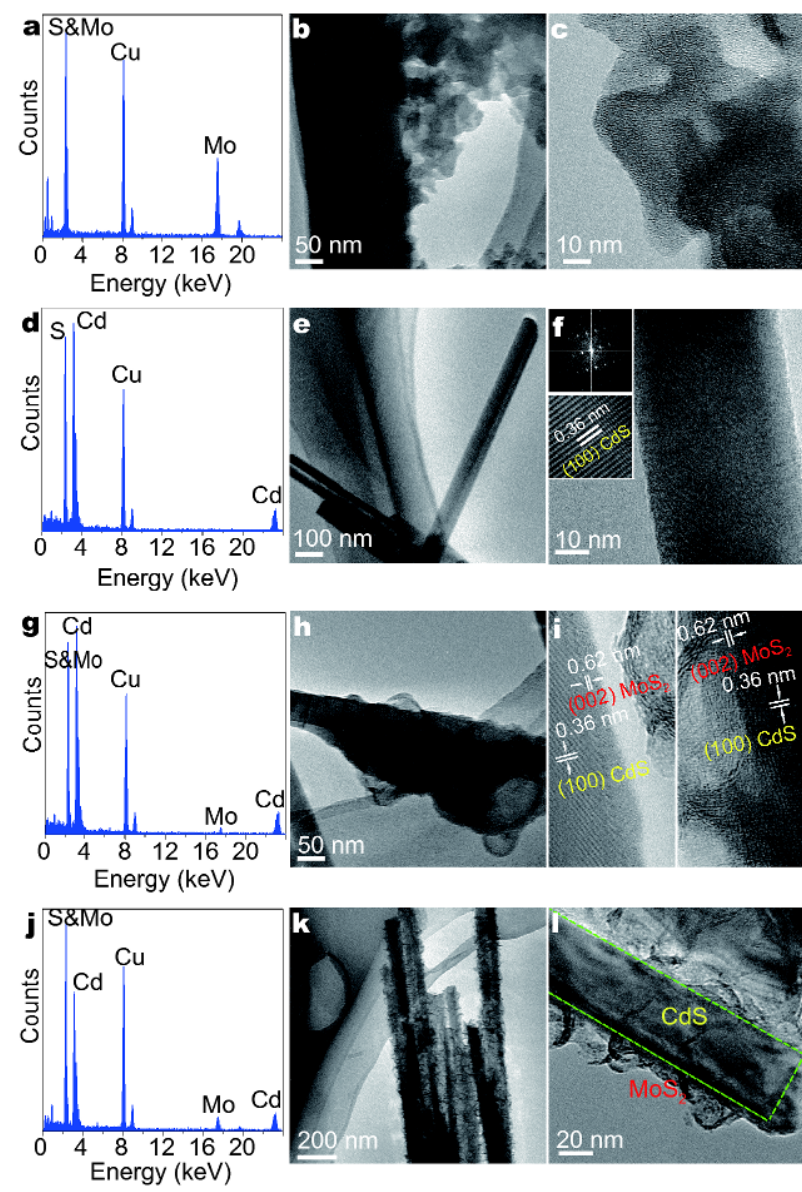

Figure 2 TEM, HRTEM images and EDS spectra of (a-c) $M_{2}$; (d-f) CdS; (g-i) $5 \%-\mathrm{MoS}_{2} / \mathrm{CdS}$; (j-1) $20 \%-\mathrm{MoS}_{2} / \mathrm{CdS}$. CdS NWs structure is highlighted in a green dashed rectangle.

templates. Fig. 2e, f show that CdS has a uniform $1 \mathrm{D}$ NWs morphology with an average diameter of 50-90 nm. Meanwhile, as shown in Fig. $2 \mathrm{f}$, the lattice spacing of $0.36 \mathrm{~nm}$ corresponds to the (100) plane of hexagonal CdS and the selected-area electron diffraction (SAED) shows a 

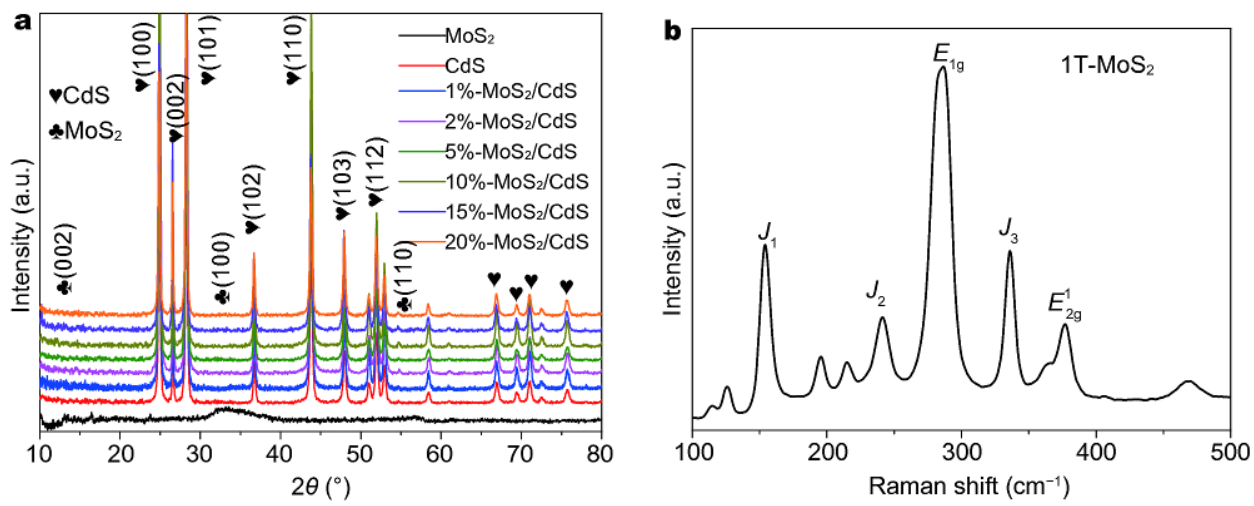

Figure 3 (a) XRD patterns of $\mathrm{MoS}_{2}$, CdS, $\mathrm{MoS}_{2} / \mathrm{CdS}$ nanocomposites; (b) Raman spectra of pure 1T-MoS. The strong diffraction peaks marked with " $\boldsymbol{~ " ~ c a n ~ b e ~ i n d e x e d ~ t o ~ t h e ~ h e x a g o n a l ~ C d S ~ ( J C P D S ~ c a r d ~ N o . ~ 6 5 - 3 4 1 4 ) ~ [ 3 2 ] , ~ t h e ~ p e a k s ~ m a r k e d ~ w i t h ~ " s " ~ c a n ~ b e ~ i n d e x e d ~ t o ~ t h e ~ h e x a g o n a l ~ M o S ~} 2$ (JCPDS card No. 37-1492) with low crystallinity [33]. (b) Raman peaks for bulk hexagonal $M_{2}$ are attributed at $E_{1 \mathrm{~g}}\left(286.5 \mathrm{~cm}^{-1}\right)$ and $E_{2 \mathrm{~g}}^{1}\left(376.8 \mathrm{~cm}^{-1}\right)$. The peaks at $153.7 \mathrm{~cm}^{-1}, 241.4 \mathrm{~cm}^{-1}$ and $337.0 \mathrm{~cm}^{-1}$, marked with $J_{1}, J_{2}$ and $J_{3}$, correspond to modes of the $1 \mathrm{~T}$ phase of $\mathrm{MoS}_{2}$ [33].

typical lattice pattern, indicating the CdS NWs are singlecrystalline. The morphology and detailed microstructure of $\mathrm{MoS}_{2} / \mathrm{CdS}$ nanocomposites are shown in Fig. 2g, 1. 1D $\mathrm{CdS}$ is covered by a thin layer $\mathrm{MoS}_{2}$ with a clear interface between $\mathrm{CdS}$ and $\mathrm{MoS}_{2}$ for $5 \%-\mathrm{MoS}_{2} / \mathrm{CdS}$ nanocomposite (Fig. 2h, i). The lattice fringes with interplanar spacings of about 0.36 and $0.62 \mathrm{~nm}$, corresponding to the (100) plane of CdS and the (002) plane of $\mathrm{MoS}_{2}$, respectively, are observed in Fig. 2i. Compared with the well-crystallinity of CdS NWs, the $\mathrm{MoS}_{2}$ layer is polycrystalline although there are some crystalline domains with random lattice fringes. A closer examination of the interface between $\mathrm{MoS}_{2}$ and $\mathrm{CdS}$ shows that the inconspicuous lattice fringes of $\mathrm{MoS}_{2}$ directly connect to the continuous lattice fringes of CdS, which is expected to facilitate the separation and transfer of photogenerated charge carriers $[27,31]$. Further increasing molar ratio of $\mathrm{MoS}_{2}$ loading to $20 \%$, as shown in Fig. 2k, l, large amounts of flocculent species are found on the surface of CdS NWs. From HRTEM image in Fig. 2l, there are no obvious lattice fringes of CdS observed, which is possibly due to excessive $\mathrm{MoS}_{2}$ loading on the CdS surface.

XRD patterns of $\mathrm{MoS}_{2}$, CdS and $\mathrm{MoS}_{2} / \mathrm{CdS}$ samples are shown in Fig. 3a. Diffraction peaks of $\mathrm{MoS}_{2} / \mathrm{CdS}$ nanocomposites are located at the same positions as pure CdS and there is no diffraction peak of $\mathrm{MoS}_{2}$ observed. Such a result is probably due to the low content, low crystallinity and broad distribution of $\mathrm{MoS}_{2}$ component. In addition, there is no noticeable shift of all diffraction peaks, implying that the change of the lattice parameters of CdS nanocrystals can be ignored [17,27]. Additionally, Raman spectra (Fig. 3b) analysis was applied to determine the crystal phase of $\mathrm{MoS}_{2}[32,33]$.
XPS analysis was carried out to gain insight into the chemical composition and binding states of the samples. Fig. 4 a shows the XPS survey spectra of $\mathrm{MoS}_{2}$, CdS and $5 \%-\mathrm{MoS}_{2} / \mathrm{CdS}$ samples, respectively $[27,34,35]$. The higher binding energy (Fig. $4 \mathrm{~b}$ ) of $\mathrm{Cd}$ in $5 \%-\mathrm{MoS}_{2} / \mathrm{CdS}$ indicates that the electronic density of $\mathrm{Cd}$ decreases with $\mathrm{MoS}_{2}$ loading. The change of Cd binding energy for 5\%$\mathrm{MoS}_{2} / \mathrm{CdS}$ indicates heterojunction formed between $\mathrm{MoS}_{2}$ and CdS, consistent with TEM results, and the possible existence of Mo-S-Cd at the interface between $\mathrm{MoS}_{2}$ and CdS. According to the Pauling scale, the electronegativity of Mo (2.16) and Cd (1.69) implies a higher electronic density of Mo than that of $\mathrm{Cd}$ in the $\mathrm{MoS}_{2} / \mathrm{CdS}$ nanocomposite, indicating electron can transfer from CdS to $\mathrm{MoS}_{2}$ at their interface [36]. When photogenerated electron of CdS is easily transferred to $\mathrm{MoS}_{2}$, the recombination probability of electron and hole pairs is decreased.

The surface area, pore volume and average pore size of $\mathrm{MoS}_{2}$, CdS and $\mathrm{MoS}_{2} / \mathrm{CdS}$ nanocomposites were also investigated, as shown in Table S1. Pristine CdS NWs displays a Brunauer-Emmett-Teller surface area $\left(S_{\mathrm{BET}}\right)$ of $27.6 \mathrm{~m}^{2} \mathrm{~g}^{-1}$, pore volume of $0.13 \mathrm{~cm}^{3} \mathrm{~g}^{-1}$ and average pore size of $15.05 \mathrm{~nm}$. The surface area, and pore volume and size firstly decrease and then increase with the continuous increase of $\mathrm{MoS}_{2}$ amount. The $S_{\mathrm{BET}}$ reduces to $13.82 \mathrm{~m}^{2} \mathrm{~g}^{-1}$ for $5 \%-\mathrm{MoS}_{2} / \mathrm{CdS}$, and the pore volume also decreases to $0.06 \mathrm{~cm}^{3} \mathrm{~g}^{-1}$, due to the whole surface of CdS NWs covered by $\mathrm{MoS}_{2}$ nanosheets. However, the $\mathrm{MoS}_{2}$ nanosheets were stacked together to form some new mesoporous and macroporous structures on the surface of CdS NWs with further increase $\mathrm{MoS}_{2}$ amount, thus result in the increase of the surface area, pore volume and size. The surface area 

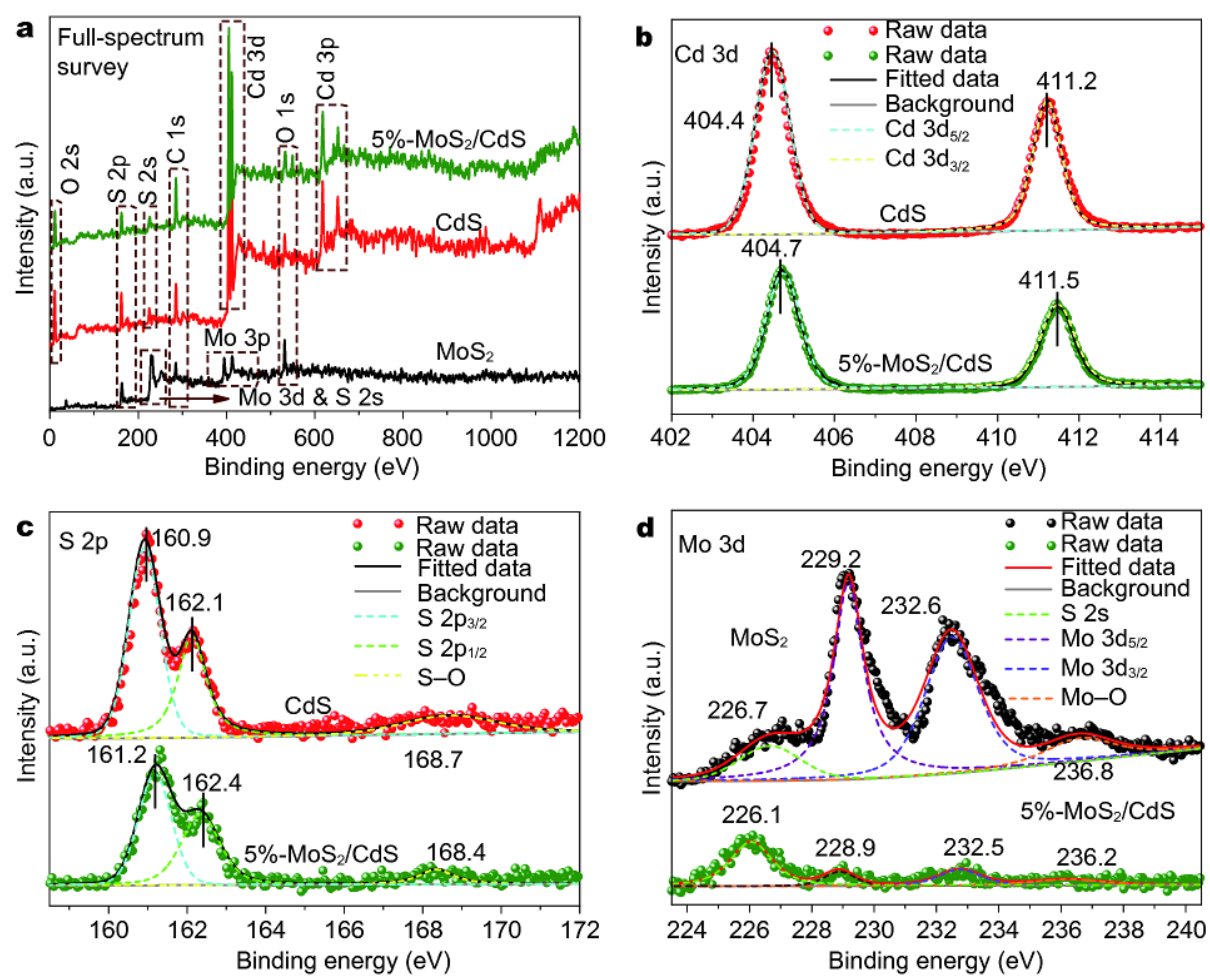

Figure 4 (a) XPS survey spectra of $\mathrm{MoS}_{2}$, CdS and 5\%-MoS $/$ CdS; (b) Cd 3d of CdS and 5\%-MoS $/ \mathrm{CdS}$; the high-resolution XPS spectra of Cd 3d for $5 \%-\mathrm{MoS}_{2} / \mathrm{CdS}$ and pure CdS exhibit two binding energy peaks at $404.7 \mathrm{eV}, 411.5 \mathrm{eV}$ and $404.4 \mathrm{eV}, 411.2 \mathrm{eV}$, respectively. (c) $\mathrm{S} 2 \mathrm{p}$ of CdS and $5 \%-$ $\mathrm{MoS}_{2} / \mathrm{CdS}$; the S 2p peaks of $5 \%-\mathrm{MoS}_{2} / \mathrm{CdS}$ located at $162.4 \mathrm{eV}\left(2 \mathrm{p}_{1 / 2}\right)$ and $161.2 \mathrm{eV}\left(2 \mathrm{p}_{3 / 2}\right)$, suggesting the existence of $\mathrm{S}^{2-}$ [27]. (d) Mo $3 \mathrm{~d}$ of MoS $\mathrm{S}_{2}$ and $5 \%-\mathrm{MoS}_{2} / \mathrm{CdS}$; the binding energy at $229.2 \mathrm{eV}$ and $232.6 \mathrm{eV}$ corresponds to $\mathrm{Mo}^{4+}$ in pure $\mathrm{MoS}_{2}$, meanwhile, $5 \%-\mathrm{MoS}_{2} / \mathrm{CdS}$ has $\mathrm{Mo} 3 \mathrm{~d}$ peaks at $228.9 \mathrm{eV}$ and $232.5 \mathrm{eV}$, lower than that of pure $\mathrm{MoS}_{2}$, which indicates its higher electronic density of $\mathrm{Mo}^{4+}$. The peaks at $236.8 \mathrm{eV}\left(\mathrm{MoS}_{2}\right)$ and $236.2 \mathrm{eV}$ $\left(5 \%-\mathrm{MoS}_{2} / \mathrm{CdS}\right)$ are assigned to the Mo (+6) $3 \mathrm{~d}$ orbit, which may be due to the exposure to air $[34,35]$.
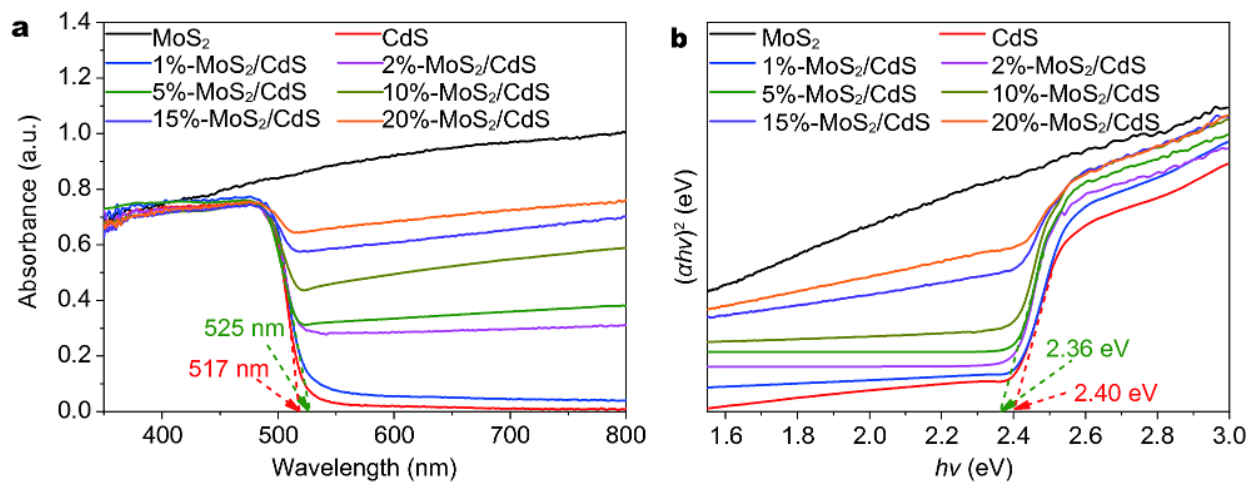

Figure $5 \mathrm{UV}$-vis diffuse reflectance spectra (a) and optical band gap energy (b) of $\mathrm{MoS}_{2}$, CdS and $\mathrm{MoS}_{2} / \mathrm{CdS}$ nanocomposites in the wavelength range of $300-800 \mathrm{~nm}$.

and porosity of the as-prepared samples displays a reverse variation trend with their photoactivity. Therefore, dramatically enhanced photocatalytic $\mathrm{H}_{2}$ evolution performance over $\mathrm{MoS}_{2} / \mathrm{CdS}$ nanocomposites does not originate from the variation of surface area and porous structures.
Fig. 5a shows the UV-vis diffuse-reflectance spectra of $\mathrm{MoS}_{2}, \mathrm{CdS}$ and $\mathrm{MoS}_{2} / \mathrm{CdS}$ in the wavelength range of 300-800 nm. Pure $\mathrm{MoS}_{2}$ shows a significant absorption edge at around $517 \mathrm{~nm}$ for pure CdS NWs, corresponding to the band gap of $\sim 2.40 \mathrm{eV}$ (Fig. 5b). The $\mathrm{MoS}_{2} / \mathrm{CdS}$ nanocomposites have an absorption inflection point and 
almost the same absorption edge with pure CdS. Taking the $5 \%-\mathrm{MoS}_{2} / \mathrm{CdS}$ nanocomposite as an example, the absorption edge is at about $525 \mathrm{~nm}$ and the bandgap of CdS was determined to be $\sim 2.36 \mathrm{eV}$ (Fig. 5b). The nearly same absorption edge indicates the bandgap of CdS is unchanged, revealing that the presence of $\mathrm{MoS}_{2}$ does not change the band structure of CdS. Meanwhile, compared to pure CdS, enhanced absorption in visible region from 500 to $800 \mathrm{~nm}$ is observed for $\mathrm{MoS}_{2} / \mathrm{CdS}$ nanocomposites. The absorption of the $\mathrm{MoS}_{2} / \mathrm{CdS}$ nanocomposites increases with the increasing amount of $\mathrm{MoS}_{2}$, which could be attributed to absorption of $\mathrm{MoS}_{2}$ [27]. Fig. S1 displays the photoluminescence (PL) spectra of $\mathrm{MoS}_{2}, \mathrm{CdS}$ and $\mathrm{MoS}_{2} / \mathrm{CdS}$ nanocomposites in the solid-state. The black $\mathrm{MoS}_{2}$ shows little emission, consistent with its expected metallic property. The spectrum for pure CdS shows a broad emission band at $525 \mathrm{~nm}$ with some weaker bands to red due to bandgap trap states. With increasing loading of $\mathrm{MoS}_{2}$ from $1 \%$ to $5 \%$, both the band-edge and trap state emissions of CdS decreased, indicating more nonradiative recombination [37], attributed to electron transfer from the conduction band of CdS to $\mathrm{MoS}_{2}$. With further increasing amount of $\mathrm{MoS}_{2}$ to about 10\%, the emissions from CdS almost disappeared, due to complete quenching by $\mathrm{MoS}_{2}$.

\section{Photoelectrochemical studies of $\mathrm{MoS}_{2}, \mathrm{CdS}$ and $\mathrm{MoS}_{2} / \mathrm{CdS}$ nanocomposites}

The photocurrent densities measured in the visible light on/off cycles are shown in Fig. 6. The pure $\mathrm{MoS}_{2}$ has almost no photocurrent response, implying no effective charge separation. The photocurrent density of $5 \%-\mathrm{MoS}_{2} /$ CdS nanocomposite was the highest, about 5.5 times higher than pristine CdS [38].

Linear sweep voltammograms (LSV) were performed in the dark and under visible light irradiation for $\mathrm{MoS}_{2}$, CdS and the $\mathrm{MoS}_{2} / \mathrm{CdS}$ nanocomposites. A higher photocurrent corresponds to a higher efficiency for hydrogen evolution [39]. Fig. 7 shows LSV plots of $\mathrm{MoS}_{2}$, CdS and $\mathrm{MoS}_{2} / \mathrm{CdS}$ nanocomposites in the dark and under visible light irradiation. Pure $\mathrm{MoS}_{2}$ and 5\%-MoS$/ \mathrm{CdS}$ nanocomposite show negligible current under dark conditions (the inset in Fig. 7). Pure $\mathrm{MoS}_{2}$ also shows negligible current response under light illumination, indicating poor activity for hydrogen evolution. However, the 5\%$\mathrm{MoS}_{2} / \mathrm{CdS}$ nanocomposite displays the highest photocurrent density under the light illumination, indicating optimal photocatalytic activity. The results indicate that the excessive $\mathrm{MoS}_{2}$ may compete with CdS for light absorption, resulting in the decrease of photogenerated

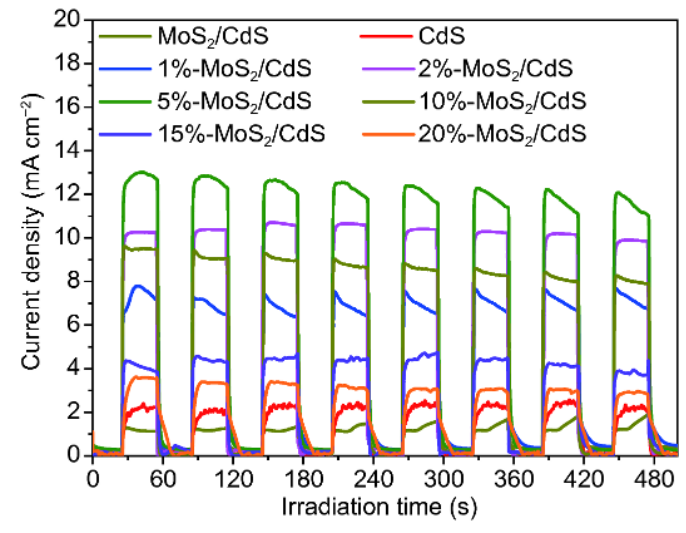

Figure 6 The transient photocurrent density of $\mathrm{MoS}_{2}, \mathrm{CdS}$ and $\mathrm{MoS}_{2} /$ $\mathrm{CdS}$ nanocomposites. The photocurrent densities of $\mathrm{MoS}_{2} / \mathrm{CdS}$ nanocomposites are higher than that of pure CdS, with the following orders: $5 \%-\mathrm{MoS}_{2} / \mathrm{CdS}>2 \%-\mathrm{MoS}_{2} / \mathrm{CdS}>10 \%-\mathrm{MoS}_{2} / \mathrm{CdS}>1 \%-\mathrm{MoS}_{2} / \mathrm{CdS}>$ $15 \%-\mathrm{MoS}_{2} / \mathrm{CdS}>20 \%-\mathrm{MoS}_{2} / \mathrm{CdS}>\mathrm{CdS}$.

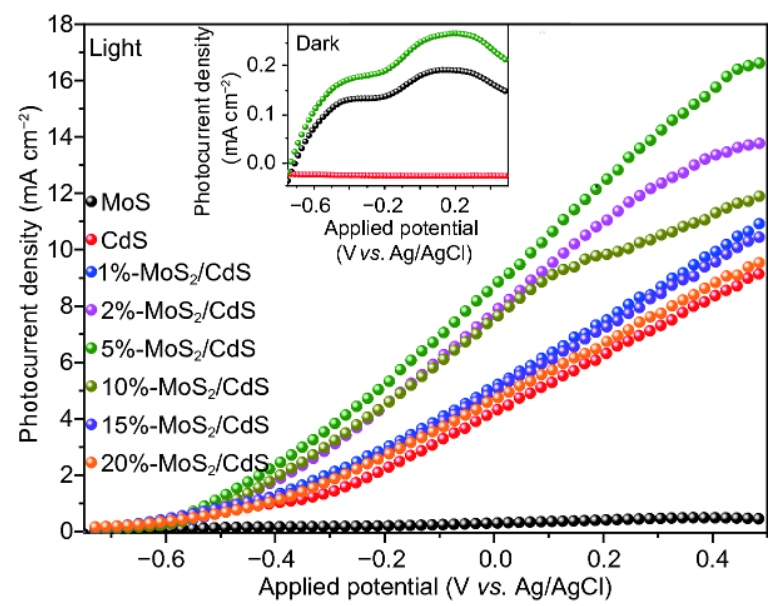

Figure 7 Photocurrent-applied potential $(J-V)$ curves of as-prepared samples in the dark and under visible light condition with scanning rate of $10 \mathrm{mV} \mathrm{s}^{-1}$.

electron and hole pairs and reducing the effective photocurrent response of $\mathrm{MoS}_{2} / \mathrm{CdS}$ nanocomposite $[9,27,40]$.

Meanwhile, electrochemical impedance spectroscopy (EIS) was applied to further understand the charge separation and transport properties of $\mathrm{MoS}_{2}, \mathrm{CdS}$ and $\mathrm{MoS}_{2} / \mathrm{CdS}$ nanocomposites (Fig. 8). In general, the surface charge transfer resistance is equivalent to the diameter of semicircular portion of the Nyquist diagrams and the smaller radius represents the lower resistance for charge transfer [41,42]. Compared to pure CdS and $\mathrm{MoS}_{2}$, the semicircle arc diameter of $\mathrm{MoS}_{2} / \mathrm{CdS}$ nanocomposites indicates faster electron transfer or lower electron transfer 

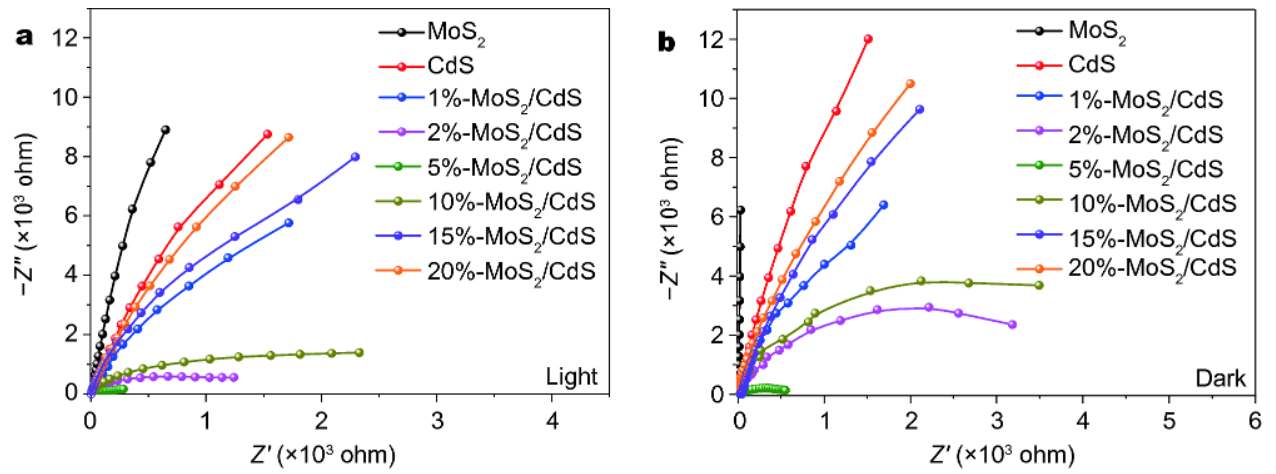

Figure 8 Electrochemical impedance spectra of Nyquist plots for $\mathrm{MoS}_{2}$, CdS and $\mathrm{MoS}_{2} / \mathrm{CdS}$ nanocomposites under visible light irradiation (a) and dark condition (b), respectively.

resistance at the surface of the photoelectrode. EIS spectra also clearly show the smaller radius of $\mathrm{MoS}_{2}$, CdS and $\mathrm{MoS}_{2} / \mathrm{CdS}$ nanocomposites under visible light irradiation than those in the dark, which further displays the photocatalytic activity of these as-prepared samples.

The slope of the linear part in the Mott-Schottky curves provides additional evidence for the enhanced PEC performance of $\mathrm{MoS}_{2} / \mathrm{CdS}$ nanocomposites. As presented in Fig. S2, pure CdS and all $\mathrm{MoS}_{2} / \mathrm{CdS}$ nanocomposites exhibit n-type conductivity. The carrier density can be calculated from the slopes of the Mott-Schottky plots using the following Equation 1:

$$
N_{d}=\left(2 / \varepsilon \varepsilon_{0} q\right)\left[\frac{\mathrm{d}\left(1 / C^{2}\right)}{\mathrm{d} V}\right]^{-1},
$$

where $\varepsilon$ is the dielectric constant of $\mathrm{MoS}_{2}$ (6.52) and CdS (8.7), $\varepsilon_{0}\left(8.854 \times 10^{-12} \mathrm{~F} \mathrm{~m}^{-1}\right)$ is the vacuum permittivity, $q$ $\left(1.603 \times 10^{-19} \mathrm{C}\right)$ is the electron charge, $N_{\mathrm{d}}$ is the carrier density and $V$ is the potential applied at the electrode, respectively. The electron density $\left(N_{\mathrm{d}}\right)$ of CdS is calculated as $6.85 \times 10^{17} \mathrm{~cm}^{-3}$, while the $N_{\mathrm{d}}$ values of $5 \%-\mathrm{MoS}_{2} /$ $\mathrm{CdS}$ and $20 \%-\mathrm{MoS}_{2} / \mathrm{CdS}$ were $9.08 \times 10^{17} \mathrm{~cm}^{-3}$ and $6.4 \times 10^{17} \mathrm{~cm}^{-3}$, respectively. The high electron density in the $5 \%-\mathrm{MoS}_{2} / \mathrm{CdS}$ is believed to be a major factor to the photocurrent density enhancement. The results are summarized in Table S2 $[43,44]$. In general, the increase of charge carrier density is associated with increased electrical conductivity $(\sigma)$ of the photoelectrode, which is given by $\sigma=e n \mu$, where $e, n$ and $\mu$ are the electronic charge, the concentration and mobility of charge carrier, respectively. A high mobility is highly favorable for improving charge separation and transport $[43,45]$.

\section{Ultrafast studies of charge carrier dynamics}

Ultrafast TA spectroscopy was used to study the charge carrier separation and transfer through the system. CdS nanaowires, $5 \%-\mathrm{MoS}_{2} / \mathrm{CdS}$ and $20 \%-\mathrm{MoS}_{2} / \mathrm{CdS}$ were excited with $390 \mathrm{~nm}$ pump laser pulses. Fig. $9 \mathrm{a}-\mathrm{c}$ show 3D and $2 \mathrm{D}$ representation of TA data as a function of probe wavelength and delay time between pump and probe pulses.

As it is shown in Fig. 9, a transient bleach (TB) feature at $480 \mathrm{~nm}$ and a broad TA feature from 500 to $700 \mathrm{~nm}$ was observed for CdS nanowires. As reported previously the transient bleach signal can be attributed to absorption of photogenerated carriers $[46,47]$. No significant difference was observed in spectral profile of CdS upon addition of $\mathrm{MoS}_{2}$ even at 20\%; however, the charge carrier lifetime changed dramatically.

Analyzing the decay of transient bleach/absorption signal can provide useful information about charge carrier dynamic of CdS with $\mathrm{MoS}_{2}$ addition. However, some non-linear dynamic processes such as exciton-exciton annihilation or Auger recombination can interfere with data interpretation. Three pulse energies $(750,323$ and $190 \mathrm{~nJ}$ per pulse) were used to study power-dependent dynamics of the nanocomposites. Because no power dependence was observed in the sample's dynamics, we analyzed the data with the highest signal to noise ratio at $750 \mathrm{~nJ}$ per pulse. Fig. 10a-c show the normalized single wavelength TB $(480 \mathrm{~nm})$ and TA $(510 \mathrm{~nm})$ signal of CdS nanowires, 5\%- $\mathrm{MoS}_{2} / \mathrm{CdS}$ and $20 \%-\mathrm{MoS}_{2} / \mathrm{CdS}$ nanocomposites, respectively, from 0 to 1,000 ps. For better comparison, transient bleach signal of all 3 samples were plotted together in Fig. 10d. The recovery of signals was fit with double exponential function and the fitting parameters are reported in Table 1.

The average recovery lifetime of CdS nanowires, 5\%$\mathrm{MoS}_{2} / \mathrm{CdS}$ and $20 \%-\mathrm{MoS}_{2} / \mathrm{CdS}$ are calculated to be $837 \mathrm{ps}, 50 \mathrm{ps}$ and $257 \mathrm{ps}$ respectively, using the following 

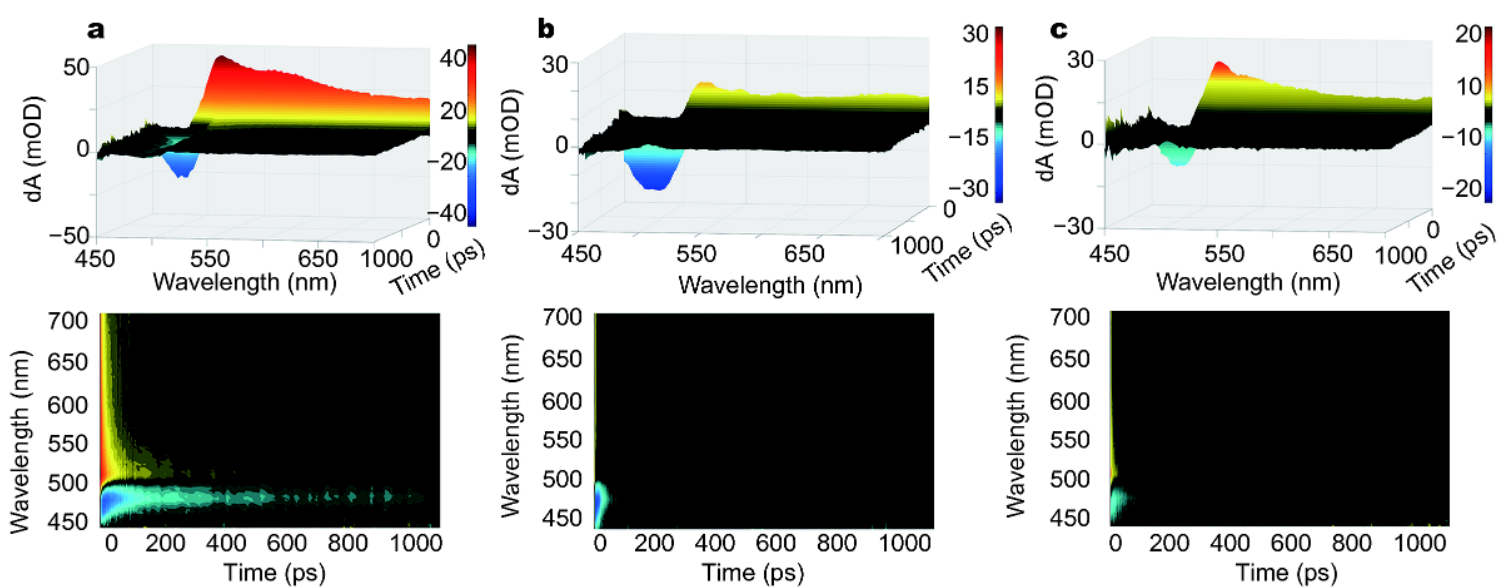

Figure 9 Representative 3D (top) and 2D (bottom) transient absorption (TA)/transient bleach (TB) profiles of (a) CdS nanowires; (b) 5\%-MoS $/$ CdS; (c) $20 \%-\mathrm{MoS}_{2} / \mathrm{CdS}$ excited with $390 \mathrm{~nm}$ pump $(750 \mathrm{~nJ} /$ pulse).
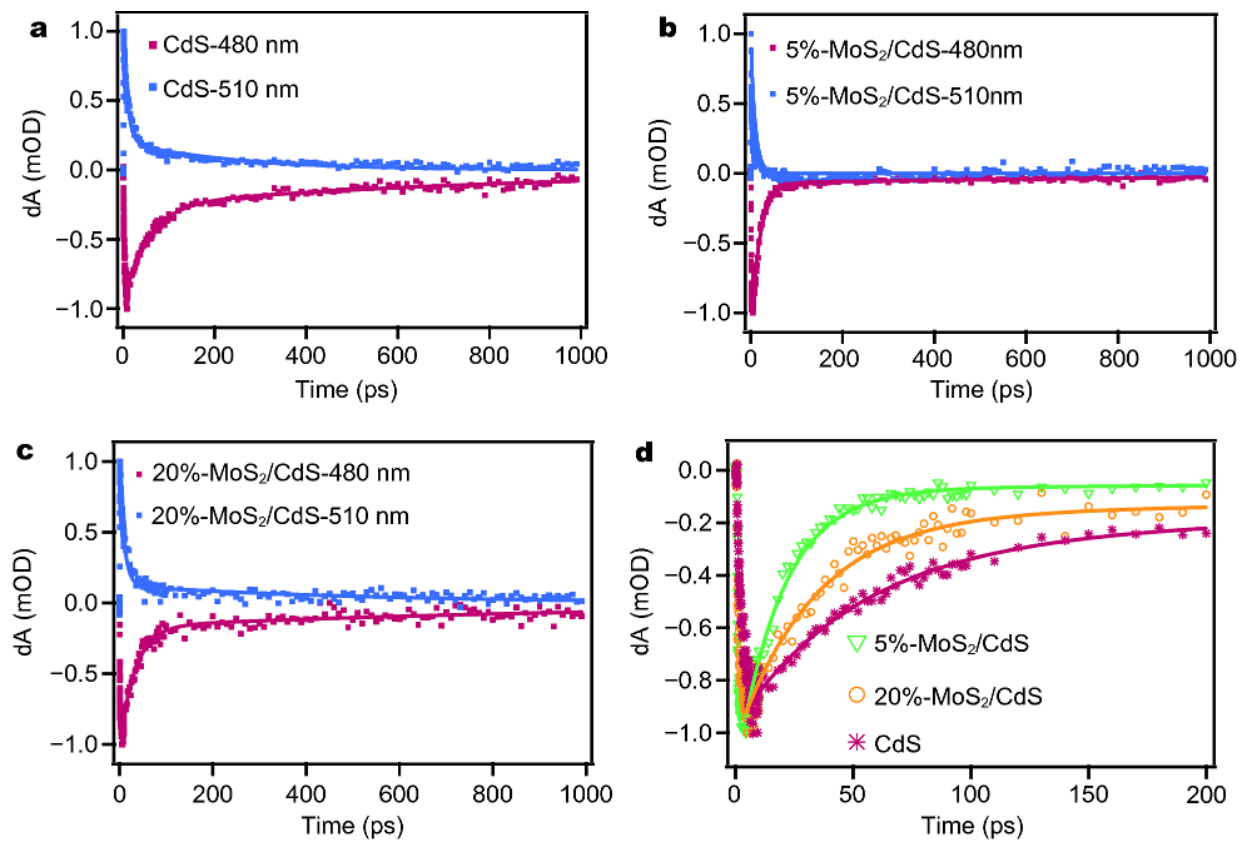

Figure 10 Normlized ultrafast transient bleach/absorption decay profile of (a) CdS nanowire; (b) 5\%- $\mathrm{MoS}_{2} / \mathrm{CdS}$; (c) $20 \%-\mathrm{MoS} / \mathrm{CdS}$; (d) transient bleach recovery of all 3 samples. The decay profiles are fitted using a double exponential function.

Table 1 Fitting parameters of transient bleach recovery of CdS, 5\%- $\mathrm{MoS}_{2} / \mathrm{CdS}$ and $20 \%-\mathrm{MoS}_{2} / \mathrm{CdS}$ fitted with double exponential function and calculated average lifetime $\langle\tau\rangle$

\begin{tabular}{ccccccc}
\hline Sample & $A_{1}$ & $\tau_{1}(\mathrm{ps})$ & $A_{2}$ & $\tau_{2}(\mathrm{ps})$ & $<\tau$ & $Y$ \\
\hline $\mathrm{CdS}$ & $-0.25 \pm 0.01$ & $52.86 \pm 2.66$ & $-0.71 \pm 0.01$ & $853 \pm 89$ & 837 & $0 \pm 0$ \\
$5 \%-\mathrm{MoS}_{2} / \mathrm{CdS}$ & $-0.95 \pm 0.01$ & $20.04 \pm 0.68$ & $0.06 \pm 0.00$ & $125 \pm 14$ & 50 & $0 \pm 0$ \\
$20 \%-\mathrm{MoS}_{2} / \mathrm{CdS}$ & $-0.86 \pm 0.01$ & $32.62 \pm 1.85$ & $-0.17 \pm 0.01$ & $360 \pm 27$ & 257 & $0 \pm 0$ \\
\hline
\end{tabular}

Equation 2:

$$
\text { Average } \tau=\frac{A_{1} \tau_{1}^{2}+A_{2} \tau_{2}^{2}}{A_{1} \tau_{1}+A_{2} \tau_{2}}
$$

As demonstrated in Fig. 12d and average lifetimes, there is significant difference in charge carrier dynamic of CdS in the presence of $\mathrm{MoS}_{2}$ on the surface. Decorating $5 \%$ 

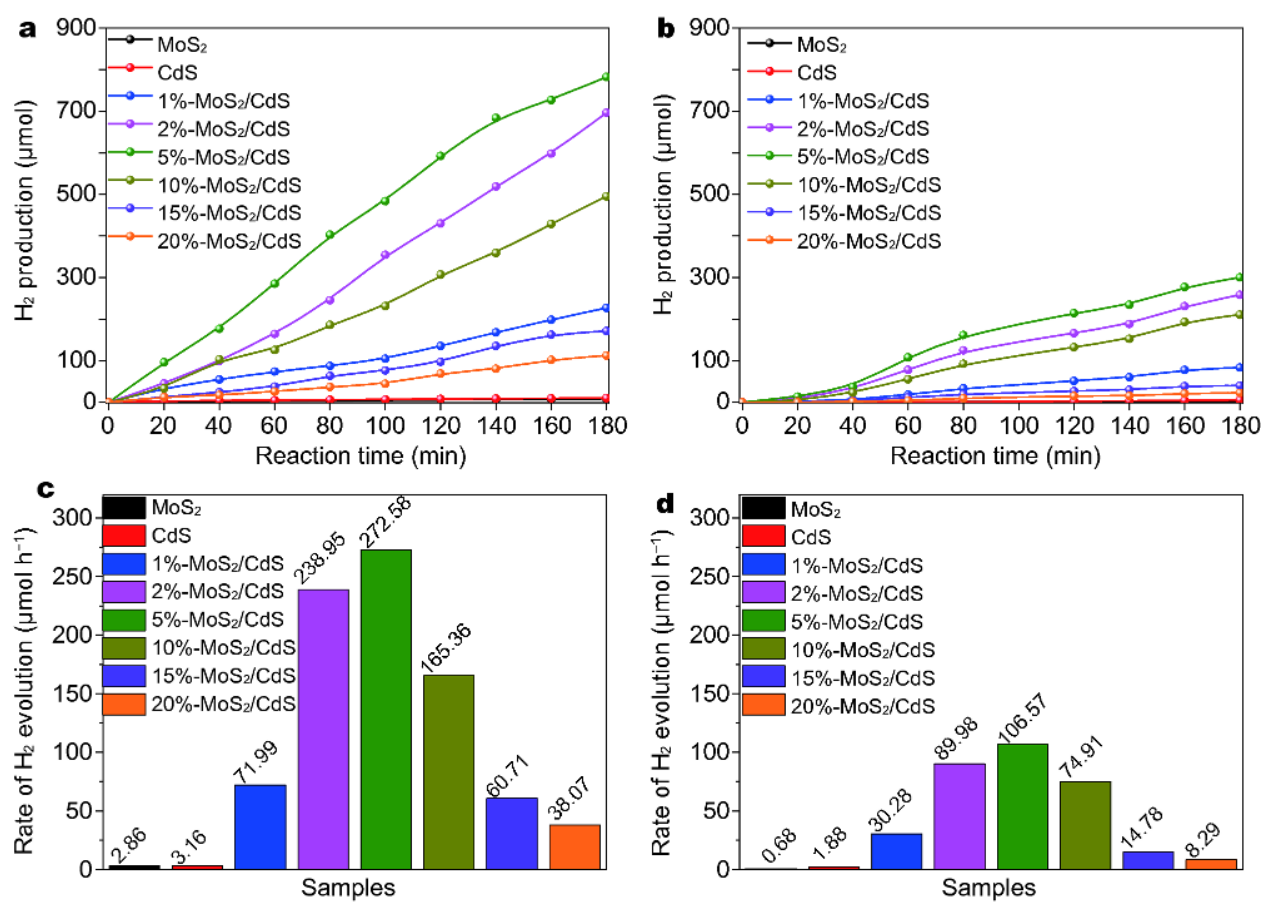

Figure 11 The photocatalytic hydrogen production activities of different samples under visible light irradiation $(\lambda \geq 400 \mathrm{~nm})$ in the presence of lactic acid and glucose aqueous solution (a, c) and lactic acid aqueous solution (b, d), respectively.

$\mathrm{MoS}_{2}$ on CdS nanowire shortened the average life time of CdS by factor of approximately 17 , attributed to efficient electron transfer from CdS to $\mathrm{MoS}_{2}$ [33]. This fast electron transfer will prevent undesirable recombination of electron-hole, promote better charge separation and improve the catalytic activity of nanocomposite for the HER reaction (Fig. 11). One may expect that higher concentration of $\mathrm{MoS}_{2}$ on CdS surface should shorten the charge carrier lifetime and improve the charge carrier separation even further. However, upon further addition of $\mathrm{MoS}_{2}$ to $20 \%$, the average lifetime now increased by factor of 5 , compared to $5 \%-\mathrm{MoS}_{2} / \mathrm{CdS}$, while the photocatalytic activity also decreased at the same time. SEM images of the $\mathrm{MoS}_{2} / \mathrm{CdS}$ nanocomposites at different ratios may help to explain this behavior. As shown in Fig. 2, a thin and uniform layer of $\mathrm{MoS}_{2}$ was coated on the surface of CdS nanowires at 5\% molar ratio, providing intimate contact for charge transfer at the heterointerface. However, by increasing the $\mathrm{MoS}_{2}$ concentration up to $20 \%$, the growth of flocculent structures may lead to reduced surface contact and charge transfer.

\section{Photocatalytic $\mathrm{H}_{2}$-evolution activity of $\mathrm{MoS}_{2}$, CdS and $\mathrm{MoS}_{2} / \mathrm{CdS}$ nanocomposites}

Photocatalytic hydrogen evolution over CdS, $\mathrm{MoS}_{2}$ and $\mathrm{MoS}_{2} / \mathrm{CdS}$ nanocomposites were evaluated under visible light irradiation $(\lambda \geq 400 \mathrm{~nm})$ in aqueous solution containing glucose and lactic acid or lactic acid alone as hole scavengers. As shown in Fig. 11, pure CdS shows a very low photocatalytic activity during the reaction process, which is attributed to fast recombination of photogenerated charge carriers and less active sites in CdS NWs. Loading $\mathrm{MoS}_{2}$ on the surface of CdS NWs significantly enhances the average rates of $\mathrm{H}_{2}$ evolution. When the theoretical molar ratio of $\mathrm{MoS}_{2}$ and CdS is $5 \%$, the $\mathrm{H}_{2}$ production rate reaches an optimal value, which is approximately 86.3 or 56.7 times higher than that of pure CdS NWs using glucose and lactic acid or lactic acid as sacrificial agent, respectively. However, further increasing amount of $\mathrm{MoS}_{2}$ in the nanocomposites leads to a decrease of $\mathrm{H}_{2}$ evolution activity, which may be attributed to excessive $\mathrm{MoS}_{2}$ that competes with CdS for light absorption. Comparing Fig. 11a with 11b, higher HER activity in the presence of glucose and lactic acid as sacrificial agent suggests that the glucose can provide an extra pathway for the fast consumption of hole, thereby improving the photocatalytic HER.

Schematic mechanism for enhanced photocatalytic $\mathrm{H}_{2}-$ evolution activity of $\mathrm{MoS}_{2} / \mathrm{CdS}$ nanocomposites

A possible mechanism for enhanced photocatalytic $\mathrm{H}_{2}$ evolution from water using $\mathrm{MoS}_{2} / \mathrm{CdS}$ nanocomposites is 


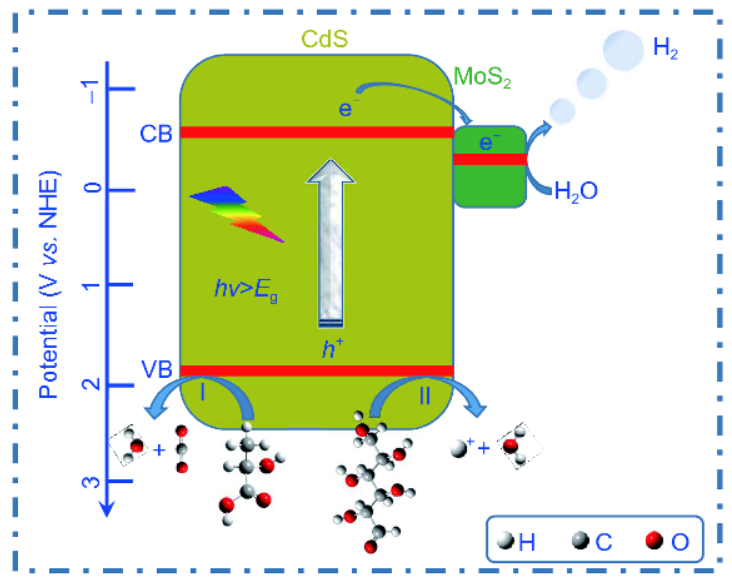

Figure 12 Scheme for the photocatalytic hydrogen production over $\mathrm{MoS}_{2} / \mathrm{CdS}$ nanocomposites under visible light.

proposed as shown in Fig. 12. Under visible light irradiation, electron-hole pairs generated in CdS NWs are quickly recombined, leading to low photoactivity. For $\mathrm{MoS}_{2} / \mathrm{CdS}$ nanocomposite, the photogenerated electrons in the conduction band (CB) of CdS can be transferred to $\mathrm{MoS}_{2}$ due to the lower energy level of $\mathrm{MoS}_{2}$ than the CB edge of CdS. Importantly, the large and intimate interfacial contact between CdS and $\mathrm{MoS}_{2}$ should facilitate the electron transfer from CdS to $\mathrm{MoS}_{2}$. The electrons transferred to $\mathrm{MoS}_{2}$ react with $\mathrm{H}_{2} \mathrm{O}$ to generate $\mathrm{H}_{2}\left(2 \mathrm{H}_{2} \mathrm{O}\right.$ $\left.+2 \mathrm{e}^{-} \rightarrow \mathrm{H}_{2}+2 \mathrm{OH}^{-}\right)$. Meanwhile, the photoinduced holes in the VB of CdS can oxidize hole sacrificial agents, as described by the pathway I/II in Fig. 12. When the lactic acid is used as only hole scavenger, the reaction products are $\mathrm{CO}_{2}$ and $\mathrm{H}_{2} \mathrm{O}$ (pathway I). When glucose and lactic acid are used as sacrificial agents together, the photogenerated holes in CdS can react with $\mathrm{OH}^{-}$, producing $\mathrm{OH}^{*}$ radicals. The $\mathrm{OH}^{*}$ radicals then react rapidly with glucose, which leads to the formation of carboxylic acid $(\mathrm{H}-\mathrm{COOH})$ and finally $\mathrm{CO}_{2}$ and $\mathrm{H}^{+}$[48]. In this process, the $\mathrm{OH}^{*}$ radicals are consumed and protons are produced simultaneously, resulting in a higher $\mathrm{H}_{2}$ production $[9,49]$ (pathway II). The overall reaction of oxidation could be depicted by $\mathrm{C}_{6} \mathrm{H}_{12} \mathrm{O}_{6}+6 \mathrm{H}_{2} \mathrm{O} \rightarrow 6 \mathrm{CO}_{2} \uparrow+12 \mathrm{H}_{2} \uparrow$.

\section{CONCLUSION}

In conclusion, a series of $\mathrm{MoS}_{2} / \mathrm{CdS}$ nanocomposites with different amounts of $1 \mathrm{~T}-\mathrm{MoS}_{2}$ have been successfully prepared using a two-step solvothermal method. Morphological and structural analyses show that $\mathrm{MoS}_{2}$ and CdS have intimate interfacial contact. The $\mathrm{MoS}_{2} / \mathrm{CdS}$ nanocomposites show enhanced PEC and HER activities compared to pure CdS NWs, among which $5 \%-\mathrm{MoS}_{2} / \mathrm{CdS}$ nanocomposite presents 5.5 times enhancement in photocurrent and 86.3 times improvement for HER using glucose and lactic acid as sacrificial agents under visible light. The interaction between $\mathrm{MoS}_{2}$ and CdS efficiently facilitates the separation and transfer of the photogenerated hole and electron pairs resulting in decreasing the average charge carrier lifetime by factor of 17 , thereby enhancing its photocatalytic $\mathrm{H}_{2}$ evolution activity. Furthermore, glucose and lactic acid as sacrificial agents are found to perform better than lactic acid alone because of more produced protons during the decomposition of glucose. This work also suggests the possibility of reforming cheap and abundant biomass feed stocks for hydrogen generation from water splitting.

Received 2 November 2017; accepted 28 November 2017; published online 19 January 2018

1 Walter MG, Warren EL, McKone JR, et al. Solar water splitting cells. Chem Rev, 2010, 110: 6446-6473

2 Katz MJ, Riha SC, Jeong NC, et al. Toward solar fuels: water splitting with sunlight and "rust"? Coord Chem Rev, 2012, 256: 2521-2529

3 Fujishima A, Honda K. Electrochemical photolysis of water at a semiconductor electrode. Nature, 1972, 238: 37-38

4 Cho IS, Chen Z, Forman AJ, et al. Branched $\mathrm{TiO}_{2}$ nanorods for photoelectrochemical hydrogen production. Nano Lett, 2011, 11: 4978-4984

5 Pu YC, Wang G, Chang KD, et al. Au nanostructure-decorated $\mathrm{TiO}_{2}$ nanowires exhibiting photoactivity across entire UV-visible region for photoelectrochemical water splitting. Nano Lett, 2013, 13: $3817-3823$

6 Li C, Fan W, Lu H, et al. Fabrication of Au@CdS/RGO/TiO heterostructure for photoelectrochemical hydrogen production. New J Chem, 2016, 40: 2287-2295

7 Zou Z, Ye J, Sayama K, et al. Direct splitting of water under visible light irradiation with an oxide semiconductor photocatalyst. Nature, 2011, 414: 625-627

8 Tsuji I, Kato $\mathrm{H}$, Kudo A. Visible-light-induced $\mathrm{H}_{2}$ evolution from an aqueous solution containing sulfide and sulfite over a $\mathrm{ZnS}$ $\mathrm{CuInS}_{2}-\mathrm{AgInS}_{2}$ solid-solution photocatalyst. Angew Chem, 2005, 117: $3631-3634$

9 Li C, Wang H, Ming J, et al. Hydrogen generation by photocatalytic reforming of glucose with heterostructured $\mathrm{CdS} / \mathrm{MoS}_{2}$ composites under visible light irradiation. Int J Hydrogen Energ, 2017, 42: 16968-16978

10 Li Y, Chen G, Zhou C, et al. A simple template-free synthesis of nanoporous $\mathrm{ZnS}-\mathrm{In}_{2} \mathrm{~S}_{3}-\mathrm{Ag}_{2} \mathrm{~S}$ solid solutions for highly efficient photocatalytic $\mathrm{H}_{2}$ evolution under visible light. Chem Commun, 2009, 414: 2020

11 Wang X, Maeda K, Chen X, et al. Polymer semiconductors for artificial photosynthesis: hydrogen evolution by mesoporous graphitic carbon nitride with visible light. J Am Chem Soc, 2009, 131: $1680-1681$

12 Liu X, Pan L, Lv T, et al. Microwave-assisted synthesis of CdSreduced graphene oxide composites for photocatalytic reduction of Cr(vi). Chem Commun, 2011, 47: 11984-11986 
13 Li Q, Guo B, Yu J, et al. Highly efficient visible-light-driven photocatalytic hydrogen production of CdS-cluster-decorated graphene nanosheets. J Am Chem Soc, 2011, 133: 10878-10884

$14 \mathrm{Hu} \mathrm{Y,} \mathrm{Gao} \mathrm{X,} \mathrm{Yu} \mathrm{L,} \mathrm{et} \mathrm{al.} \mathrm{Carbon-coated} \mathrm{CdS} \mathrm{petalous} \mathrm{nanos-}$ tructures with enhanced photostability and photocatalytic activity. Angew Chem Int Ed, 2013, 52: 5636-5639

$15 \mathrm{Xu} \mathrm{Y}$, Zhao W, Xu R, et al. Synthesis of ultrathin CdS nanosheets as efficient visible-light-driven water splitting photocatalysts for hydrogen evolution. Chem Commun, 2013, 49: 9803-9805

16 Zheng W, Feng W, Zhang X, et al. Anisotropic growth of nonlayered CdS on $\mathrm{MoS}_{2}$ monolayer for functional vertical heterostructures. Adv Funct Mater, 2016, 26: 2648-2654

17 Li Y, Wang L, Cai T, et al. Glucose-assisted synthesize 1D/2D nearly vertical CdS/ $\mathrm{MoS}_{2}$ heterostructures for efficient photocatalytic hydrogen evolution. Chem Eng J, 2017, 321: 366-374

18 Si H, Kang Z, Liao Q, et al. Design and tailoring of patterned ZnO nanostructures for energy conversion applications. Sci China Mater, 2017, 60: 793-810

19 Yan H, Yang J, Ma G, et al. Visible-light-driven hydrogen production with extremely high quantum efficiency on Pt-PdS/CdS photocatalyst. J Catal, 2009, 266: 165-168

20 Merki D, Hu X. Recent developments of molybdenum and tungsten sulfides as hydrogen evolution catalysts. Energy Environ Sci, 2011, 4: 3878-3888

21 Zong X, Yan H, Wu G, et al. Enhancement of photocatalytic $\mathrm{H}_{2}$ evolution on CdS by loading $\mathrm{MoS}_{2}$ as cocatalyst under visible light irradiation. J Am Chem Soc, 2008, 130: 7176-7177

22 Zong X, Wu G, Yan H, et al. Photocatalytic $\mathrm{H}_{2}$ evolution on $\mathrm{MoS}_{2} /$ CdS catalysts under visible light irradiation. J Phys Chem C, 2010, 114: 1963-1968

23 Chen G, Li D, Li F, et al. Ball-milling combined calcination synthesis of $\mathrm{MoS}_{2} / \mathrm{CdS}$ photocatalysts for high photocatalytic $\mathrm{H}_{2}$ evolution activity under visible light irradiation. Appl Catal AGeneral, 2012, 443-444: 138-144

24 Chen J, Wu XJ, Yin L, et al. One-pot synthesis of CdS nanocrystals hybridized with single-layer transition-metal dichalcogenide nanosheets for efficient photocatalytic hydrogen evolution. Angew Chem Int Ed, 2015, 54: 1210-1214

25 Chang K, Li M, Wang T, et al. Drastic layer-number-dependent activity enhancement in photocatalytic $\mathrm{H}_{2}$ evolution over $n \mathrm{MoS}_{2}$ /CdS $(n \geq 1)$ under visible light. Adv Energy Mater, 2015, 5: 1402279

26 He J, Chen L, Wang F, et al. CdS nanowires decorated with ultrathin $\mathrm{MoS}_{2}$ nanosheets as an efficient photocatalyst for hydrogen evolution. ChemSusChem, 2016, 9: 624-630

27 Han B, Liu S, Zhang N, et al. One-dimensional CdS@MoS 2 coreshell nanowires for boosted photocatalytic hydrogen evolution under visible light. Appl Catal B-Environ, 2017, 202: 298-304

28 Ma S, Xie J, Wen J, et al. Constructing 2D layered hybrid CdS nanosheets $/ \mathrm{MoS}_{2}$ heterojunctions for enhanced visible-light photocatalytic $\mathrm{H}_{2}$ generation. Appl Surf Sci, 2017, 391: 580-591

29 Liu C, Dasgupta NP, Yang P. Semiconductor nanowires for artificial photosynthesis. Chem Mater, 2014, 26: 415-422

30 Han S, Pu YC, Zheng L, et al. Shell-thickness dependent electron transfer and relaxation in type-II core-shell $\mathrm{CdS} / \mathrm{TiO}_{2}$ structures with optimized photoelectrochemical performance. J Mater Chem A, 2015, 3: 22627-22635

31 Zhan X, Wang Q, Wang F, et al. Composition-tuned $\mathrm{ZnO} / \mathrm{Zn}_{x}$ $\mathrm{Cd}_{1-x} \mathrm{Te}$ core/shell nanowires array with broad spectral absorption from UV to NIR for hydrogen generation. ACS Appl Mater In- terfaces, 2014, 6: 2878-2883

32 Zhu G, Bao C, Liu Y, et al. Self-regulated route to ternary hybrid nanocrystals of $\mathrm{Ag}-\mathrm{Ag}_{2} \mathrm{~S}-\mathrm{CdS}$ with near-infrared photoluminescence and enhanced photothermal conversion. Nanoscale, 2014, 6: 11147-11156

33 Liu Q, Shang Q, Khalil A, et al. In situ integration of a metallic 1T$\mathrm{MoS}_{2} / \mathrm{CdS}$ heterostructure as a means to promote visible-lightdriven photocatalytic hydrogen evolution. ChemCatChem, 2016, 8: 2614-2619

34 Weber T, Muijsers JC, van Wolput JHMC, et al. Basic reaction steps in the sulfidation of crystalline $\mathrm{MoO}_{3}$ to $\mathrm{MoS}_{2}$, as studied by $\mathrm{X}$-ray photoelectron and infrared emission spectroscopy. J Phys Chem, 1996, 100: 14144-14150

35 Zhao L, Jia J, Yang Z, et al. One-step synthesis of CdS nanoparticles/MoS 2 nanosheets heterostructure on porous molybdenum sheet for enhanced photocatalytic $\mathrm{H}_{2}$ evolution. Appl Catal BEnviron, 2017, 210: 290-296

$36 \mathrm{Xu} \mathrm{J}$, Cao X. Characterization and mechanism of MoS2/CdS composite photocatalyst used for hydrogen production from water splitting under visible light. Chem Eng J, 2015, 260: 642-648

37 Yang Y, Rodríguez-Córdoba W, Xiang X, et al. Strong electronic coupling and ultrafast electron transfer between $\mathrm{PbS}$ quantum dots and $\mathrm{TiO}_{2}$ nanocrystalline films. Nano Lett, 2012, 12: 303-309

38 Zhang J, Wang L, Liu X, et al. High-performance CdS-ZnS coreshell nanorod array photoelectrode for photoelectrochemical hydrogen generation. J Mater Chem A, 2015, 3: 535-541

39 Li J, Cushing SK, Zheng P, et al. Solar hydrogen generation by a $\mathrm{CdS}-\mathrm{Au}-\mathrm{TiO}_{2}$ sandwich nanorod array enhanced with Au nanoparticle as electron relay and plasmonic photosensitizer. J Am Chem Soc, 2014, 136: 8438-8449

40 Shen L, Luo M, Liu Y, et al. Noble-metal-free $\mathrm{MoS}_{2}$ co-catalyst decorated UiO-66/CdS hybrids for efficient photocatalytic $\mathrm{H}_{2}$ production. Appl Catal B-Environ, 2015, 166-167: 445-453

41 Li G, Wu L, Li F, et al. Photoelectrocatalytic degradation of organic pollutants via a CdS quantum dots enhanced $\mathrm{TiO}_{2}$ nanotube array electrode under visible light irradiation. Nanoscale, 2013, 5: 21182125

42 Bai Z, Yan X, Li Y, et al. 3D-branched $\mathrm{ZnO/CdS} \mathrm{nanowire} \mathrm{arrays}$ for solar water splitting and the service safety research. Adv Energy Mater, 2016, 6: 1501459

43 Zhan $\mathrm{F}, \mathrm{Li} \mathrm{J}, \mathrm{Li} \mathrm{W}$, et al. In situ synthesis of $\mathrm{CdS} / \mathrm{CdWO}_{4} / \mathrm{WO}_{3}$ heterojunction films with enhanced photoelectrochemical properties. J Power Sources, 2016, 325: 591-597

44 Wang G, Ling $\mathrm{Y}$, Wheeler DA, et al. Facile synthesis of highly photoactive $\alpha-\mathrm{Fe}_{2} \mathrm{O}_{3}$-based films for water oxidation. Nano Lett, 2011, 11: 3503-3509

45 Zhou M, Bao J, Xu Y, et al. Photoelectrodes based upon $\mathrm{Mo:BiVO}$ inverse opals for photoelectrochemical water splitting. ACS Nano, 2014, 8: 7088-7098

46 Wheeler DA, Zhang JZ. Exciton dynamics in semiconductor nanocrystals. Adv Mater, 2013, 25: 2878-2896

47 Shen S, Guo P, Wheeler DA, et al. Physical and photoelectrochemical properties of $\mathrm{Zr}$-doped hematite nanorod arrays. Nanoscale, 2013, 5: 9867-9874

48 Caravaca A, Jones W, Hardacre $\mathrm{C}$, et al. $\mathrm{H}_{2}$ production by the photocatalytic reforming of cellulose and raw biomass using $\mathrm{Ni}$, Pd, Pt and Au on titania. Proc R Soc A, 2016, 472: 20160054

49 Wang L, Wang W, Shang M, et al. Enhanced photocatalytic hydrogen evolution under visible light over $\mathrm{Cd}_{1-x} \mathrm{Zn}_{x} \mathrm{~S}$ solid solution with cubic zinc blend phase. Int J Hydrogen Energ, 2010, 35: 19-25 
Acknowledgements This work was financially supported by the National Natural Science Foundation of China (51402126). Zhang JZ is grateful to support from Delta Dental Health Associates, NASA through MACES (NNX15AQ01A), and UCSC Committee on Research Special Research Grant.

Author contributions Wang $\mathrm{H}$ and Zhang JZ conceived the idea of the project. Ying L conducted the synthesis of materials. Bonabi S, Li C and Allen A performed the characterizations and photocatalytic tests.
Wang $\mathrm{H}, \mathrm{Li} \mathrm{C}$ and Bonabi $\mathrm{S}$ analyzed the data. Wang $\mathrm{H}$, Bonabi $\mathrm{S}$ and Zhang JZ drafted the manuscript. Wang $\mathrm{H}$ and Bonabi $\mathrm{S}$ contributed equally to this work. All authors participated the general discussion of the manuscript.

Conflict of interest The authors declare no conflict of interest.

Supplementary information Supporting data are available in the online version of the paper.

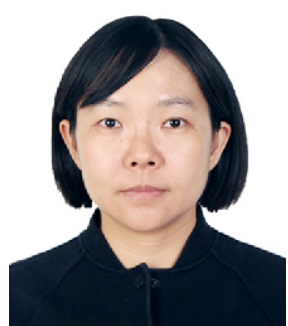

Hongmei Wang received her BSc degree in 2001 and MSc degree in 2004 from China University of Geosciences (Wuhan), China. In 2007, she received his PhD degree from Wuhan University, China. Then, she had her visiting scholar experience from Wuhan University and University of California, Santa Cruz. Currently, she is an associate professor at Jiaxing University. Her research interests focus on the semiconductor-based nanomaterials for energy conversion and storage, and photocatalysis.
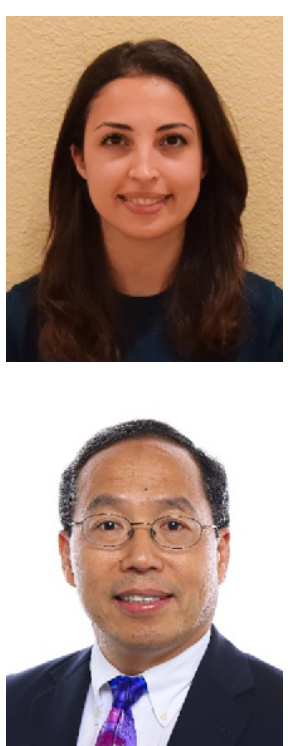

Sara Bonabi Naghadeh received her BSc degree in applied Chemistry and her MSc degree in Nano Chemistry from University of Tehran, Tehran, Iran. She is currently PhD student and research assistant in Prof. Zhang's group at University of California, Santa Cruz. Her research interests include design, synthesis and characterization of nanomaterials for various applications such as chemical and biological sensors, cancer detection, photothermal therapy and photovoltaics.
Jin Zhong Zhang received his BSc degree in Chemistry from Fudan University, Shanghai, China, in 1983 and his PhD in physical chemistry from University of Washington, Seattle in 1989. He was a postdoctoral research fellow at University of California Berkeley from 1989 to 1992. In 1992, he joined the faculty at UC Santa Cruz, where he is currently full professor of chemistry and biochemistry. Zhang's recent research interests focus on design, synthesis, characterization, and exploration of applications of advanced materials including semiconductors, metals, and metal oxide nanomaterials, particularly in the areas of solar energy conversion, solid state lighting, sensing, and biomedical detection/therapy. He has authored 300 publications and three books. Zhang has been serving as a senior editor for JPC published by ACS since 2004. He is a Fellow of AAAS, APS, and ACS. He is the recipient of the 2014 Richard A. Glenn Award of the ACS Energy and Fuel Division.

\title{
$\mathrm{MoS}_{2}$ 纳米片/CdS纳米线复合光催化剂的制备及其光电化学和光催化活性研究
}

\author{
王红梅 ${ }^{1,2 \dagger^{*}}$, Sara Bonabi Naghadeh ${ }^{2 \dagger}$, 李春鹤 ${ }^{3}$, 应露 ${ }^{1}, A^{\prime} L^{2}$ ster Allen ${ }^{2}$, 张金中 ${ }^{2^{*}}$
}

摘要 本论文通过两步水热法合成了 $\mathrm{MoS}_{2}$ 纳米片/CdS纳米线复合光催化剂. 采用扫描电子显微镜、透射电子显微镜、X射线粉末衍射 仪、拉曼光谱仪、X射线光电子能谱仪、比表面积分析仪、紫外可见漫反射光谱仪、荧光光谱方法和光电化学测试对复合光催化剂进行 了表征. 研究表明复合光催化剂的性能和 $M_{0}$ 负载量的多少密切相关. 当 $M_{0} S_{2}$ 的负载量为 $5 \mathrm{~mol} \%$ 时复合光催化剂具有最优的光学、光电 化学和光催化产氢活性. 与纯的CdS纳米线相比, 优化后的复合光催化剂以葡萄糖和乳酸为空穴牺牲剂, 光电流提高了 5.5 倍, 光催化产氢 活性提高了74倍, 这主要归因于 $\mathrm{MoS}_{2}$ 纳米片和 $\mathrm{CdS}$ 纳米线之间的紧密接触有利于提高电荷的分离效率. 为了进一步理解光电化学和光催 化活性提高的机理, 采用瞬态吸收光谱仪深入探究了电荷分离和转移的动力学过程. 该工作不仅涉及了具有优良光电化学和光催化活性 的复合光催化剂的制备方法, 而且展示了葡萄糖在光解水产氢中的应用. 